\title{
Linguistic Knowledge Aspects in Academic Reading: Challenges and Deployed Strategies by English-Major Undergraduates at a Jordanian Institution of Higher Education
}

\author{
Abeer H Albashtawi ${ }^{1}$, Paramaswari Jaganathan ${ }^{1} \&$ Manjet Singh ${ }^{1}$ \\ ${ }^{1}$ School of Languages, Literacies and Translation, Universiti Sains Malaysia, Penang, Malaysia \\ Correspondence: Abeer H Albashtawi, School of Languages, Literacies and Translation, Universiti Sains \\ Malaysia, Penang, Malaysia. E-mail: zonahsoon@yahoo.com
}

Received: June 9, 2016

Accepted: July 7, 2016

Online Published: July 26, 2016

doi:10.5539/hes.v6n3p61

URL: http://dx.doi.org/10.5539/hes.v6n3p61

\begin{abstract}
This study aimed to investigate the linguistic knowledge aspect in academic reading, the challenges and the deployed strategies by English major undergraduates at a Jordanian institution of higher education. The importance of the study is attributed to the importance of the academic reading at university which is closely related to the academic achievement across the different academic disciplines. Data were collected by administering a questionnaire among English major students at the Hashemite University in the year 2016. The number of the respondents was 297. The data collected were analysed for its descriptive statistics, Post Hoc Tests, Scheffe Method, and frequency using the SPSS software. Cronbach's alpha of the reliability coefficient was .93 to the difficulties of reading and .87 was to the strategies deployed by the students, which indicated high internal consistency reliability. Results showed that students faced difficulties related to their insufficient knowledge of text-structure, constructing meaning, and fluent reading. The study revealed that students most employed strategies were the metacognitive followed by the social ones. The cognitive strategies were the least to be used among the students. The study provided some pedagogical implications to be considered.
\end{abstract}

Keywords: academic reading, challenge, linguistic knowledge, strategies, practices

\section{Introduction}

Teaching English as a Second Language (SL) or a Foreign Language (FL) necessitates an understanding of the context of situation to avoid different problems. Within the context of this Jordanian study, English is taught as a FL as it is a medium of instruction in the institutions of Higher Education in most majors in the colleges of Arts, Science, and Applied Sciences. Thus, mastering the English language is a demand that is required by university students because it plays an important role in affecting their overall success. Students are aware of the importance of the English language in their academic life. However, they still have different difficulties in mastering it (Asassfeh et al., 2012).

There are many different factors that contribute to the students' inability of using the English language appropriately. For example, practicing the academic English language by Jordanian students is limited to the classroom where the instructors are Arabic native speaker. Furthermore, graduated high school students are not ready yet to deal with the advanced kinds of readings at the tertiary level (Freahat \& Al-Faoury, 2014).

Professors at universities proposed that students were taught the English skills properly and thus they are not going to teach these skills (Hermida, 2009). However, most students have not been prepared well to academic reading at the tertiary level. Also, the differences between the Arabic and the English lingual systems form a barrier that do not let the students feel free when using the English language. The cultural mismatch between the east and the west appear as the most common mistake of the English language usage. Abdul Haq (1982) states "that there are general outcries about the continuous deterioration of the standards of the English proficiency of students among school teachers, university instructors, and all who concerned with English language teaching", which is consistent with the results of Asassfeh et al. (2012) that Jordanian students are still suffering from different English language problems.

The present paper aimed to classify the linguistic academic reading problems which are faced by university students as academic reading is one of the most important skills (Freahat \& Al-Faoury, 2014) that students rely 
on in their academic life at university. Different reasons contribute to the inability to avoid these problems. Most of these are related to their insufficient linguistic knowledge. Yet, strategies could be utilized to avoid these problems.

\subsection{Statement of the Problem}

Previous literature shows that undergraduate EFL learners in Jordan are still below the mastery level of the English language proficiency due to many problems in (listening, speaking, reading, and writing) (Al-Shboul et al., 2013; Asassfeh et al., 2012). The demands of reading increase as students are shifting from high school level to the tertiary level. Hence, academic reading becomes a challenge that hinders them from understanding the printed materials, particularly because English is being relied on heavily as a medium of instruction in most major courses in the Jordanian universities.

Al-Beckry and Reddy (2005) have stated that reading problems are attributed to the misconception of the reading process, insufficient linguistic knowledge in general and reading practices in particular, and due to the differences between the Arabic and the English spelling sound systems. Fender (2003) has also examined the difficulties at the level of word-reading, and has found in his contrastive study between the Arab and the Japanese students that most difficulties were related to word recognition. In another study conducted by Al-Shboul et al. (2015), reading difficulties have been attributed to different personal and text-feature linguistic factors. Students are afraid of making errors, worry about unknown vocabulary, and unfamiliar topics and culture. The findings of this study would contribute to the existing literature in reading at the undergraduate level particularly in Jordan.

\subsection{Rationale of the Study}

Undergraduate EFL learners' exposure to the English language is limited to the classroom. Thus, academic reading comprises their main path to acquire knowledge in their content areas. Learning the academic language in addition to the content areas knowledge simultaneously form a challenge to the students. Thus, understanding the difficulties is a priority that must be considered in the instructors agenda to come up with solutions that help students, who are particularly below the level of the English language proficiency, in meeting these challenges.

\subsection{Relevant Scholarship}

Academic reading is discussed by Sengupta (2002) as a purposeful and critical reading of lengthy academic reading texts for completing the study of specific subject areas. The nature of academic reading texts poses different kinds of difficulties that hinder our students from understanding the meaning of the text. Academic reading relies heavily on the academic language which is distinguished by its formality, difficult vocabulary, precision and concision, and its structures (Chamot \& O'Malley, 1996; Cummins, 1983, 1984). Academic language which is context reduced forces the teachers to think on effective and helpful strategies that can increase the students English language proficiency.

Constructing meaning is the ultimate goal of all readers. Reading is a complex process because it requires an interaction between the text, the reader, and the writer. Reading skill is comprised of a number of sub-skills. These sub-skills work together to touch the comprehension. The acquisition of these sub-skills necessitates different distinct knowledges as well as practices of reading in the second or foreign language. Thus, the different sources that compose the reading process themselves are the sources of problems. However, students who have difficulties in meeting the demands of the academic reading, may still have the chance to deal successfully with the different kinds of the advanced academic readings by the use of appropriate strategies.

Knowing the components of reading skill could help in identifying the sources of reading difficulties. Thus, looking thoroughly into the sub-skills that compose reading skill is important in examining the specific contributions of the linguistic knowledge in the reading process. These distinct sub-skills work together to get the meaning from the text. However, each distinct sub-skill needs a distinct linguistic knowledge.

Carr et al. (1990) refer to reading as a cognitive process that forms a product of complex information-processing system, involving closely mental operations that are distinguished by their different functions. These functions work together to facilitate the process of understanding to build the meaning from the printed material. Thus, the primary goal of the approach is to understand the scope of the cognitive skills underlying reading and to examine their functional interactions.

Successful reading depends on the effective interaction of the extracted information from the text and the reader's prior knowledge activation (Koda, 1992). In this perspective, reading involves three major components: extracting information from the printed material, integrating the extracted into phrases, sentences, and 
paragraphs, and synthesizing the text-information with the prior knowledge (Koda, 2007). Thus, different elements contribute in making the meaning from the text.

The first element refers to the knowledge of decoding. It states the fluency in extracting the phonological and morphological information from a printed word (Koda, 2005). Good readers could recognize many words quickly and get their overall meanings and sounds without processing individual letters (Ehri et al., 1991; Ehri, 1994; Seidenberg \& McClelland, 1989). Phonological processing which refers to the involvement in accessing, storing, and manipulating phonological information (Torgesen \& Burgess, 1998) is also involved in decoding knowledge as well as morphological knowledge which enables people from guessing the meaning of the new words by analyzing them into small units guessed by analyzing a word's morphological constituents (Verhoeven $\&$ Carlisle, 2006) and vocabulary knowledge.

The second element refers to text informational constructing which includes the syntactic knowledge of the discourse markers, and the knowledge of the text-structure. Comprehending sentences enable the reader from gradual integration of the lexical information in away to reach the overall comprehension of the larger linguistic units such as phrases and clauses. Discourse markers or connectors are also considered important to build coherence in the text, primarily they create coherence across sentences. Their main function is to express the underlying semantic relation between the two sentences. The surface structure of the text provides clear understanding to the coherence relations among the elements of the text. These elements are located in apparent positions to show their importance and they do connect with other text segments in a clear way (Goldman \& Rakestraw, 2000). This kind of knowledge can facilitate identifying clearly the main points in the text and thus improves the general comprehension of the text.

The third element explains the reader-model construction which operates on locally assembled text segments; therefore, global text comprehension is severely impaired by inaccurate and incomplete local text information. Although reader-model building is mostly conceptual and involves little amount of linguistic processing, but it is still affected indirectly by the linguistic knowledge (Koda, 2007).

\subsection{Related Studies to Academic Reading Difficulties}

Shen (2013) has investigated the difficulties of academic reading met by the EFL learners at the undergraduate level. The participants in the study from the English and non-English majors. The results have indicated that academic reading difficulties are attributed to the deficiency in their language ability and their inability to comprehend content material. Vocabulary has been perceived to be the primary challenge especially when students come to reading in their content-areas. Moreover, learners' reading strategies and needs are various across disciplines, and thus most learners have showed a desire for greater support (e.g., highlighting key points, and pre-teaching terminologies, sentence structures, grammar, and reading strategies).

In a similar study, Snow (2010) has stated that academic language is distinguished by its concision, precision, and authority. These goals could be achieved by using sophisticated words and complex grammatical constructions that can create reading comprehension difficulties and thus prohibit learning. The results have indicated that students need help in learning academic vocabulary and the way to process the academic language if they are to become independent learners of science. Scientific texts have been proved to be more difficult than the English language art and this strengthen the fact that academic language is a source of problems. Snow's (2010) findings are consistent with Qian (2002) findings where he has concluded the important role of vocabulary to improve reading performance.

Furthermore, Hinkel (2006) views that EFL learners need to have knowledge of the language of the text in order to succeed at reading; otherwise, they will not be able to process any of the information they are reading. Successful reading necessitates the student's ability in determining the meaning and the form of the word first, then putting it together with the sentence all within a few seconds. EFL learners struggle with this because they cannot process at the speed necessary for success.

Some scholars have also focused on some of the behaviors and practices that should be considered to improve reading (e.g., Indirjit, 2014; Al-Beckay \& Reddy, 2015). Indirjit (2014) has stated that lack of literacy skills including reading causes problems for living, working and survival in general. For example, research in Malaysia has proven that Malaysian do not read enough and the mainstream of readers are students reading books for examinations rather than knowledge and pleasure. The trends of readings have focused on the importance of reading and the way of conditioning this behavior towards a habitual way of life amongst Malaysian students. His study has concluded that some of the methods of improving reading among students could be utilized. 
Another study by Manjet (2014) has also stressed the importance of finding solutions to help students avoid their academic reading difficulties which are encountered by international students particularly Arab students. Her research concludes that students' difficulties are attributed to the lack of knowledge in the content areas as well as to the fact that using English as a medium of instruction is not their first language.

Al-Shboul et al. (2013) have investigated the sources of foreign language anxiety in general among the undergraduate students at Yarmouk University, Jordan. The study has indicated that the sources of anxiety that influence the acquisition of certain specific language skills such as reading in particular are attributed to personal and text factors. Data were collected through observation, semi-structured interviews and diaries from six informants with different levels of English language proficiency. The results have revealed that personal factors were due to the fear of making errors and worry about reading effects. However, the factors which are related to text were due to unknown vocabulary, unfamiliar topic, and unfamiliar culture. The results of the study are consistent with other studies that have been conducted to determine the sources of difficulties. Al-Seghayer (2014), has revealed the same results in addition to including some more factors that affect the proficiency of the English language such as the components of curriculum, and pedagogical and administrative constraints.

In short, Rababah (2002) has attributed all the previous difficulties to the weakness of the English language learners in general, such as lack of knowledge on the part of school graduates when they join the university and learners' motivation, as well as English language department majors more specifically, such as school and English language department curricula, teaching methodology, lack of the target language environment (Zughoul, 1983).

\subsection{Objectives of the Study}

The purposes of the study are:

1) To investigate the linguistic knowledge aspect as a challenge in academic reading encountered by the English major undergraduates at the Hashemite University.

2) To find the strategies employed by the English major undergraduates at the Hashemite University to meet these challenges.

\section{Method}

In the current quantitative study, the researcher developed a questionnaire to investiagate the academic reading difficulties met by the undergraduate EFL students, as a less researched area, in one of the institutions of higher education in Jordan. The study was conducted in the year 2016, at the Department of English Language, at the Hashemite University. The dependent variable is the academic reading practices which are affected by the difficulties faced by the undergraduates and the strategies they use to overcome their difficulties.

\subsection{Participants' Characteristics}

All the students were undergraduate and homogeneous with regard to their native Arabic language, years of studying the English language before enrolling at the university, and their English language major. They were in the age range of $18-22$ years old.

\subsection{Sampling Procedures}

The target population is 1300 university students at the Department of English Language, at the Hashemite University in Jordan. The participants constitute the freshman, sophomore, junior, and senior students.The sampling method in this study was a stratified random sampling consisted of four subpopulation. Equal numbers were selected randomly from the subpopulation to generate stratified equal-sized strata. The total sample consisted of 297 subjects, study different courses from different levels (see Table 1).

Table 1. Classification of the total population (1300) included in the sample (297)

\begin{tabular}{cll}
\hline Level & & Stratum \\
\hline Freshman & Equal Random Selection & Stratum (75) \\
Sophomore & Equal Random Selection & Stratum (80) \\
Junior & Equal Random Selection & Stratum (73) \\
Senior & Equal Random Selection & Stratum (69) \\
\hline
\end{tabular}




\subsection{Measures}

The researcher has carefully developed a questionnaire to collect the data that answer the questions of the study. The questionnaire was divided into three sections; A, B, and C. Section A was to collect the demographic data. Section B was to collect data regarding the challenges of academic reading, and section $\mathrm{C}$ was to collect data about the strategies used by the students to meet these challenges. The questionnaire consisted of 47 items. It has been validated by a specialized jury at the Hashemite university in Jordan and University of Science Malaysia. 3 items were deleted, 6 were modified. The final version of the questionnaire consisted of 44 items. The students were asked to assess the level of difficulty in the academic reading challenges on a 5-point Likert scale from 1 (very difficult) to 5 (very easy) and 1 (strongly disagree) to 5 (agree) regarding the used strategies by the students. The calculated Cronbach's alpha of the reliability coefficient was 93 to the difficulties of reading and 87 was to the strategies deployed by the students, which indicated high internal consistency reliability.

\subsection{Data Collection and Analysis}

The questionnaire was administered during class time in courses selected randomly from the four academic levels at the Department of English during the second semester in the year 2016. All the participants have voluntarily completed the survey. Instructions have been provided to the respondents on the first page of the questionnaire and confidentiality has been respected by informing the respondents that the responses would be used only for research purposes. The data collected were subjected to descriptive statistics, Post Hoc Tests, Scheffe Method, and frequency using the SPSS software.

\section{Results}

To answer the question of the study, means and standard deviations were computed and presented in Tables 3,4 , 5.

\subsection{Participants' Distribution}

Table 2 shows the distribution of the students according to their year of study. Frequencies are converted into percentages. The stratified random sample is representative to the target population of the study. They are nearly equal in number.

Table 2. Distribution of the students according to the year of study

\begin{tabular}{cccc}
\hline \multicolumn{2}{c}{ Year of Study } & Freq. & Percent\% \\
\hline Validity & Freshman & 75 & 25.3 \\
& Sophomore & 80 & 26.9 \\
& Junior & 73 & 24.6 \\
& Senior & 69 & 23.2 \\
& Total & 297 & 100.0 \\
\hline
\end{tabular}

\subsection{Challenges of Academic Reading}

297 respondents from English Language and Literature and Literature and Cultural Studies programs at the Department of English at the Hashemite University used a Likert scale ranging from 1 (Very difficult) to 5 (Very easy) to assess the degree of difficulty they encountered in the 30 items on academic reading in the questionnaire.

Table 3 shows the level of difficulties in the academic reading encountered by the freshman, sophomore, junior, and senior.

According to the variable of year, undergraduate students have great difficulties in the three investigated domains of text-structure (Mean of difficulties=3.26), text-information building (Mean=3.35), and decoding knowledge (Mean=3.46).

However, decoding knowledge appeared to be the most problematic area which students suffer from. Senior students have less difficulties than the others. This shows the effect of training as students advance in level.Senior students difficulties' mean in text-structure knowledge was 3.32 when compared to freshman whose mean was 2.99. Also, the mean of the difficulties related to information-building in the senior level was 3.18 when compared to the freshman whose mean was 3.48. Furthermore, the mean of the decoding knowledge for 
the senior students was 3.44. However, the mean of the difficulties in the decoding knowledge faced by freshman was 3.51. The results of the study indicate that students' text-structure knowledge and information-building knowledge improve better when compared to the decoding knowledge. Thus, more efforts must be made to help students in this particular area.

A well-noticed finding in the present study is related to the junior students whose difficulties were most than freshman. Particular reasons lie behind this phenomenon which must be focused on. Furthermore, some items single items related to understanding the meaning of the words and guessing the meaning from the context formed as great challenges to the student.

Table 3. Means and standard deviations according to year variable

\begin{tabular}{|c|c|c|c|c|}
\hline & Level & $\mathrm{N}$ & Mean & Std. Deviation \\
\hline \multirow[t]{5}{*}{ Text structure knowledge } & Freshman & 75 & 3.32 & .703 \\
\hline & Sophomore & 80 & 3.33 & .688 \\
\hline & Junior & 73 & 3.38 & .778 \\
\hline & Senior & 69 & 2.99 & .744 \\
\hline & Total & 297 & 3.26 & .740 \\
\hline \multirow[t]{5}{*}{ Text information Building } & Freshman & 75 & 3.48 & .734 \\
\hline & Sophomore & 80 & 3.29 & .749 \\
\hline & Junior & 73 & 3.44 & .649 \\
\hline & Senior & 69 & 3.18 & .726 \\
\hline & Total & 297 & 3.35 & .723 \\
\hline \multirow[t]{5}{*}{ Decoding knowledge } & Freshman & 75 & 3.51 & .731 \\
\hline & Sophomore & 80 & 3.38 & .767 \\
\hline & Junior & 73 & 3.51 & .706 \\
\hline & Senior & 69 & 3.44 & .614 \\
\hline & Total & 297 & 3.46 & .708 \\
\hline \multirow[t]{5}{*}{ Tot difficulties } & Freshman & 75 & 3.43 & .666 \\
\hline & Sophomore & 80 & 3.33 & .687 \\
\hline & Junior & 73 & 3.44 & .645 \\
\hline & Senior & 69 & 3.19 & .631 \\
\hline & Total & 297 & 3.35 & .663 \\
\hline \multirow[t]{5}{*}{ Meta cognitive } & Freshman & 75 & 3.63 & .640 \\
\hline & Sophomore & 80 & 3.48 & .817 \\
\hline & Junior & 73 & 3.56 & .712 \\
\hline & Senior & 69 & 3.68 & .635 \\
\hline & Total & 297 & 3.58 & .709 \\
\hline \multirow[t]{5}{*}{ Cognitive } & Freshman & 75 & 3.41 & .851 \\
\hline & Sophomore & 80 & 3.45 & .806 \\
\hline & Junior & 73 & 3.61 & .810 \\
\hline & Senior & 69 & 3.23 & .849 \\
\hline & Total & 297 & 3.43 & .835 \\
\hline \multirow[t]{2}{*}{ Social } & Freshman & 75 & 3.74 & .847 \\
\hline & Sophomore & 80 & 3.58 & .911 \\
\hline
\end{tabular}




\begin{tabular}{ccccc}
\hline & Junior & 73 & 3.67 & .842 \\
& Senior & 69 & 4.04 & .771 \\
& Total & 297 & 3.75 & .860 \\
Strategies & Freshman & 75 & 3.59 & .693 \\
& Sophomore & 80 & 3.50 & .782 \\
& Junior & 73 & 3.62 & .721 \\
& Senior & 69 & 3.65 & .601 \\
& Total & 297 & 3.59 & .704 \\
\hline
\end{tabular}

Table 3 shows a slight variance in the means of the post test according to year, to find out whether there are statistical significant differences in these means, one way ANOVA was conducted and the results are shown in Table 3.

Table 4 shows there are statistically at $(\alpha=0.05)$ in Text structure knowledge, Text information Building and Social due to year variable, to find pair wise multiple comparison, post hoc test using scheffe method was used as in Table 5, while no statistically significant differences were found in the other variables.

Table 4. One way ANOVA results related to their year of study

\begin{tabular}{|c|c|c|c|c|c|c|}
\hline & & Sum of Squares & Df & Mean Square & $\mathrm{F}$ & Sig. \\
\hline \multirow[t]{3}{*}{ Text structure knowledge } & Between Groups & 7.023 & 3 & 2.341 & 4.417 & .005 \\
\hline & Within Groups & 155.280 & 293 & .530 & & \\
\hline & Total & 162.302 & 296 & & & \\
\hline \multirow[t]{3}{*}{ Text information Building } & Between Groups & 4.149 & 3 & 1.383 & 2.694 & .046 \\
\hline & Within Groups & 150.437 & 293 & .513 & & \\
\hline & Total & 154.586 & 296 & & & \\
\hline \multirow[t]{3}{*}{ Decoding knowledge } & Between Groups & .787 & 3 & .262 & .521 & .668 \\
\hline & Within Groups & 147.485 & 293 & .503 & & \\
\hline & Total & 148.273 & 296 & & & \\
\hline \multirow[t]{3}{*}{ Tot difficulties } & Between Groups & 2.915 & 3 & .972 & 2.239 & .084 \\
\hline & Within Groups & 127.133 & 293 & .434 & & \\
\hline & Total & 130.048 & 296 & & & \\
\hline \multirow[t]{3}{*}{ Meta cognitive } & Between Groups & 1.824 & 3 & .608 & 1.213 & .305 \\
\hline & Within Groups & 146.926 & 293 & .501 & & \\
\hline & Total & 148.750 & 296 & & & \\
\hline \multirow[t]{3}{*}{ Cognitive } & Between Groups & 5.010 & 3 & 1.670 & 2.432 & .065 \\
\hline & Within Groups & 201.158 & 293 & .687 & & \\
\hline & Total & 206.167 & 296 & & & \\
\hline \multirow[t]{3}{*}{ Social } & Between Groups & 8.822 & 3 & 2.941 & 4.099 & .007 \\
\hline & Within Groups & 210.179 & 293 & .717 & & \\
\hline & Total & 219.001 & 296 & & & \\
\hline \multirow[t]{3}{*}{ Strategies } & Between Groups & .914 & 3 & .305 & .611 & .608 \\
\hline & Within Groups & 145.984 & 293 & .498 & & \\
\hline & Total & 146.897 & 296 & & & \\
\hline
\end{tabular}


Table 5. Means and standard deviation of the strategies deployed by the students from different levels

\begin{tabular}{llccc}
\hline Strategy & Students' Year of Study & N & Mean & Std. Deviation \\
\hline Meta cognitive & Freshman & 75 & 3.63 & .640 \\
& Sophomore & 80 & 3.48 & .817 \\
& Junior & 73 & 3.56 & .712 \\
& Senior & 69 & 3.68 & .635 \\
Cognitive & Total & 297 & 3.58 & .709 \\
& Freshman & 75 & 3.41 & .851 \\
& Sophomore & 80 & 3.45 & .806 \\
& Junior & 73 & 3.61 & .810 \\
Social & Senior & 69 & 3.23 & .849 \\
& Total & 297 & 3.43 & .835 \\
& Freshman & 75 & 3.74 & .847 \\
& Sophomore & 80 & 3.58 & .911 \\
& Junior & 73 & 3.67 & .842 \\
& Senior & 69 & 4.04 & .771 \\
& Total & 297 & 3.75 & .860 \\
& Freshman & 75 & 3.59 & .693 \\
& Sophomore & 80 & 3.50 & .782 \\
& Junior & 73 & 3.62 & .721 \\
& Senior & 69 & 3.65 & .601 \\
& Total & 297 & 3.59 & .704 \\
\hline
\end{tabular}

Table 5 shows up the results of the strategies deployed by the students from the different levels to solve the problems they encounter when they come across academic reading difficulties.

Based on the frequency count, the findings indicate that most students from the different levels tend to use mate cognitive strategies (the mean=3.58) and social strategies (the mean=3.75), meanwhile the least preferred strategies were the cognitive ones (the mean=3.43). Senior students tend to utilize strategies more than all other students. The total mean for the use of all strategies deployed by senior students was 3.65 when compared to freshman, sophomore, and junior whose total means for the use of all strategies were 3.59, 3.50, and 3.62 respectively. Senior students were the least among all other levels to use the cognitive strategies where the mean was 3.23. However, they were the most among all other levels to use the social strategies.

\section{Discussion}

The present study found that undergraduate Jordanian students have many difficulties which are closely related to different aspects of their linguistic knowledge when they come to academic reading. Students from different academic levels have these difficulties although the results indicate that senior students' difficulties are less than students in the other levels, and this indicates that the more practice the students receive on dealing with academic texts during their university study the better they become in mastering the skill of academic reading.

The results of the study showed that students' most noticed problems were related to their inability to recognize the genre of the text whether it is expository or argumentative, followed by the students' inability to guess the meaning of the words, understanding the relationship between the concepts, scanning the text quickly to find information, recognizing the writer's point of view, reading the words fluently, linking the previous knowledge with the new topic, and recognizing the concluding sentence. Asassfeh et al. (2011) refer to the students' inadequate linguistic competence that prohibits them from depending on the contextual clues to get meaning from the printed material.

Furthermore, reading quickly is a challenge that blocks comprehension of the text and impedes students from reaching the meaning easily. Inderjit (2014) shows that most students read for information and exams as well as 
they avoid reading for pleasure. This indicates that adopting reading as a habit would enable students to become more fluent in reading and as result their overall academic reading competence would become better.

Reading as a task provides students with the feeling that it is a tough duty, while reading for pleasure makes them read without stopping. Thus, it is a crucial issue to enhance the concept of reading for pleasure in a society and show its effect on improving the students' mastery of academic reading which is always limited only to their classrooms.

The results of the study were similar to Mokhtari (2005) in that students' inadequate vocabulary knowledge prohibits them from understanding the text. Hence, they view that their vocabulary knowledge must be enlarged to improve reading as a result. The subjects in the present study could not guess the meaning of the new words. However, vocabulary knowledge could be increased as students could be taught to employ overcoming strategies to reach the ultimate goal of reading which is comprehension.

The results of the study showed that students are aware of the names of strategies but vary in the degree of using them. Students showed their preference and familiarity to the use of metacognitive and social strategies on the expense of the cognitive strategies. The use of metacognitive strategies is attributed to the teachers' practices. Teachers' daily use of the metacognitive strategies, like asking the students for brainstorming, planning, linking the topic of the lesson with the previous knowledge, encourages the students' automatic practice of the use of these strategies. The same for social strategies like cooperative learning which is always encouraged by teachers and educators. However, cognitive strategies perceived as the least ones to be used and this is supported by Al-Shaboul et al. (2010), because these strategies need patience to be learnt as well as need time and training. They need more efforts, students avoid using these strategies as they are not used to practice using them. Cognitive strategies are normally associated with the individual learning tasks that enable students later on to transfer them to other similar learning tasks (Brown \& Palincsar, 1982; cited in O'Malley, 1985). Thus, if students are given enough training on the use of the cognitive strategies they might learn how to transfer using them into other similar tasks. It is also stressed by research that transference of strategy training to new tasks can be increased by using both cognitive strategies with appropriate metacognitive strategies and support strategies.

Students can be helped in avoiding academic reading difficulties by learning them how to apply appropriately the different strategies. They must be learnt explicitly how to make match between the task to be performed and the suitable strategy to be performed accordingly (Chamot, 2005). Constructing meaning from the text neccessiates the linguistic knowledge together with the procedural knowledge (part of it is the use of strategies) could help in making inferences to reach comprehension.

In brief, students' immature practices of reading which are strongly related to the students' culture and their context of learning should be reconsidered to create good readers who are able to read, understand, and analyze critically. Reading should be encouraged as a habitual action. Also, training the students on the use of strategies could solve many of their problems in academic reading, and thus learning strategies' use should be supported by all faculty members across the different disciplines at universities.

\section{Conclusions}

This study revealed that English major undergraduate students have many difficulties in academic reading which are mainly attributed to their insufficient linguistic knowledge. These sub-skills form the skill of reading. Yet, students can overcome most of their difficulties by deploying different strategies. These strategies can be learnt. Thus, faculty members must utilize the use of various strategies that can help students, particularly the cognitive ones as they are the least to be used among the students. Cognitive strategies would be helpful to avoid the problems of decoding knowledge. The reasons behind not using these cognitive strategies must be researched in the future as academic reading at the university level is somehow complex and depends mainly on the academic language which is distinguished by its complexity. Furthermore, bringing up reading as a habit should be reconsidered starting from the basic stages in the schools. Students have to be encouraged to read extensively till they can develop their academic reading. They must be encouraged by teachers, families, policy-makers, and the whole society. 


\section{References}

Abdul Haq, F. (1982). An analysis of syntactic errors in the composition of Jordanian secondary students (Unpublished master's thesis). Yarmouk University, Jordan.

Al-Seghayer, K. (2014). The Four Most Common Constraints Affecting English Teaching in Saudi Arabia. International Journal of English Linguistics, 4(5), 17. http://dx.doi.org/10.5539/ijel.v4n5p17

Al-Shaboul et al. (2010). Jordanian Students Learning English: Strategy Deployment. The Buckingham Journal of Language and Linguistics, 3, 101-120.

Al-Shboul et al. (2013). Foreign Language Reading Anxiety in a Jordanian EFL Context: A Qualitative Study. English Language Teaching, 6(6), 38. http://dx.doi.org/10.5539/elt.v6n6p38

Asassfeh et al. (2012). Communicative Language Teaching in an EFL Context: Learners' Attitudes and Perceived Implementation. Journal of Language Teaching and Research, 3(3), 525-535. $\mathrm{http} / /$ :dx.doi.org/10.4304/j1tr.3.3.525-535

Carr et al. (1990). Cognitive skill maps and cognitive skill profiles: Componential analysis of individual differences in children's reading efficiency.

Chamot, A. U. (2005). Language learning strategy instruction: Current issues and research. Annual review of applied linguistics, 25, 112-130. http://dx.doi.org/10.1017/s0267190505000061

Chamot, A. U., \& O’Malley, J. M. (1996). The Cognitive Academic Language Learning Approach: A Model for Linguistically Diverse Classrooms. The Elementary School Journal, 259-273. http://dx.doi.org/10.1086/461827

Cummins. (1983). The Nature of Psychological Explanation. Retrieved from http://philpapers.org/go.pl?id=CUMTNO\&proxyId=\&u=http\%3A\%2F\%2Fdx.doi.org\%2F10.1086\%2F289 349

Cummins. (1984). Bilingualism and special education: Issues in assessment and pedagogy (Vol. 6). Multilingual Matters Clevedon.

Ehri et al. (1991). Development of the ability to read words. Handbook of reading research, 2, 383-417.

Ehri, L. C. (1994). Development of the ability to read words: Update.

Fender, M. (2003). English Word Recognition and Word Integration Skills of Native Arabic and Japanese Speaking Learners of English as a Second Language. Applied Psycholinguistics, 24(2), 289-315. http://dx.doi.org/10.1017/S014271640300016X

Freahat, N. M., \& Al-Faoury, O. H. (2014). Jordanian High School EFL Teachers' and University EFL Instructors' perceptions of the reading comprehension content in EFL textbooks. Theory and Practice in Language Studies, 4(11), 2231. http://dx.doi.org/10.4304/tpls.4.11.2231-2242

Goldman, S. R., \& Rakestraw, J. A. (2000). Structural aspects of constructing meaning from text. Handbook of reading research, 3, 311-335.

Hermida, D. (2009). The Importance of Teaching Academic Reading Skills in First-Year University Courses. The International Journal of Research and Review, 3. http://dx.doi.org/10.2139/ssrn.1419247

Hinkel, E. (2006). Current Perspectives on Teaching the Four Skills. Tesol Quarterly, 40(1), 109-131. http://dx.doi.org/10.2307/40264513

Inderjit, S. (2014). Reading Trends and Improving Reading Skills among Students in Malaysia. International Journal of Research in Social Sciences, 3(5), 70-81.

Koda, K. (1992). The Effects of Lower - Level Processing Skills on FL Reading Performance: Implications for $\begin{array}{lllll}\text { Instruction. The } \quad \text { Modern } & \text { Language Journal, }\end{array}$ http://dx.doi.org/10.1111/j.1540-4781.1992.tb05400.x

Koda, K. (2005). Insights into second language reading: A cross-linguistic approach. Cambridge University Press. http://dx.doi.org/10.1017/cbo9781139524841

Koda, K. (2007). Reading and Language Learning: Crosslinguistic Constraints on Second Language Reading Development. Language learning, 57(1), 1-44. http://dx.doi.org/10.1111/0023-8333.101997010-i1 
Manjet, K. M. S. (2014). Challenges in Academic Reading and Overcoming Strategies in Taught Master Programmes: A Case Study of International Graduate Students in Malaysia. Higher Education Studies, 4(4), 76. http://dx.doi.org/10.5539/hes.v4n4p76

O'Malley et al. (1985). Learning Strategy Applications with Students of English as a Second Language. TESOL quarterly, 19(3). http://dx.doi.org/10.2307/3586278

Qian, D. D. (2002). Investigating the Relationship between Vocabulary Knowledge and Academic Reading Performance: An Assessment Perspective. Language learning, 52(3), 513-536. http://dx.doi.org/10.1111/1467-9922.00193

Rababah, G. (2002). Communication Problems Facing Arab Learners of English.

Seidenberg, M. S., \& McClelland, J. L. (1989). A Distributed, Developmental Model of Word Recognition and Naming. Psychological review, 96(4), 523. http://dx.doi.org/10.1037/0033-295X.96.4.523

Sengupta, S. (2002). Developing Academic Reading at Tertiary Level: A Longitudinal Study Tracing Conceptual Change. The reading matrix, 2(1).

Shen, M. Y. (2013). Toward an Understanding of Technical University EFL Learners' Academic Reading Difficulties, Strategies, and Needs. Electronic Journal of Foreign Language Teaching, 10(1), 70-79.

Snow, C. E. (2010). Academic Language and the Challenge of Reading. Science, 1182597(450), 328. http://dx.doi.org/10.1126/science.1182596

Torgesen, J. K., \& Burgess, S. R. (1998). Consistency of Reading-Related Phonological Processes throughout Early Childhood: Evidence from Longitudinal-Correlational and Instructional Studies. Word recognition in beginning literacy, 161-188.

Zughoul, M. (1983). The unbalanced program of the English department in the Arab world. Paper presented at the First Conference on the Problems of Teaching English Language and Literature at Arab Universities, Amman, Jordan: University of Jordan.

\section{Copyrights}

Copyright for this article is retained by the author(s), with first publication rights granted to the journal.

This is an open-access article distributed under the terms and conditions of the Creative Commons Attribution license (http://creativecommons.org/licenses/by/3.0/). 